\title{
The relation between hypointense core, microvascular obstruction and intramyocardial haemorrhage in acute reperfused myocardial infarction assessed by cardiac magnetic resonance imaging
}

\author{
Diana Kandler • Christian Lücke • Matthias Grothoff • Claudia Andres • \\ Lukas Lehmkuhl • Stefan Nitzsche • Franziska Riese • Meinhard Mende • \\ Suzanne de Waha • Steffen Desch • Philipp Lurz • Ingo Eitel • Matthias Gutberlet
}

Received: 11 October 2013 / Revised: 19 June 2014 / Accepted: 4 July 2014 /Published online: 6 August 2014

(C) The Author(s) 2014. This article is published with open access at Springerlink.com

\begin{abstract}
Background Intramyocardial haemorrhage (IMH) and microvascular obstruction (MVO) represent reperfusion injury after reperfused ST-elevation myocardial infarction (STEMI) with prognostic impact and "hypointense core" (HIC) appearance in $\mathrm{T}_{2}$-weighted images. We aimed to distinguish between IMH and MVO by using $\mathrm{T}_{2}{ }^{*}$-weighted cardiovascular magnetic resonance imaging (CMR) and analysed influencing factors for IMH development.

Methods and results A total of 151 patients with acute STEMI underwent CMR after primary angioplasty. $\mathrm{T}_{2}$-STIR sequences were used to identify HIC, late gadolinium enhancement to visualise $\mathrm{MVO}$ and $\mathrm{T}_{2}{ }^{*}$-weighted sequences to detect IMH. $\mathrm{IMH}^{+} / \mathrm{IMH}^{-}$patients were compared considering infarct size, myocardial salvage, thrombolysis in myocardial infarction (TIMI) flow, reperfusion time, ventricular volumes, function and pre-interventional medication. Seventy-six patients $(50 \%)$ were $\mathrm{IMH}^{+}, 82(54 \%)$ demonstrated HIC and 100 (66\%) MVO. IMH was detectable without HIC in $16 \%$, without MVO in $5 \%$ and HIC without MVO in $6 \%$. Multivariable analyses revealed that IMH was associated with
\end{abstract}

D. Kandler • C. Lücke · M. Grothoff · C. Andres · L. Lehmkuhl •

S. Nitzsche $\cdot$ F. Riese $\cdot$ M. Gutberlet $(\triangle)$

Department of Diagnostic and Interventional Radiology, University

Leipzig - Heart Centre, Strümpellstraße 39, 04289 Leipzig, Germany

e-mail: matthias.gutberlet@herzzentrum-leipzig.de

M. Mende

Coordination Centre for Clinical Trials, University Leipzig, Leipzig,

Germany

S. de Waha $\cdot$ S. Desch $\cdot$ P. Lurz $\cdot$ I. Eitel

Department of Internal Medicine/ Cardiology, University

Leipzig - Heart Centre, Leipzig, Germany significant lower left ventricular ejection fraction and myocardial salvage index, larger left ventricular volume and infarct size. Patients with TIMI flow grade $\leq 1$ before angioplasty demonstrated IMH significantly more often.

Conclusions IMH is associated with impaired left ventricular function and higher infarct size. $\mathrm{T}_{2}$ and $\mathrm{HIC}$ imaging showed moderate agreement for IMH detection. $\mathrm{T}_{2}{ }^{*}$ imaging might be the preferred CMR imaging method for comprehensive IMH assessment.

Key Points

- Intramyocardial haemorrhage is a common finding in patients with acute reperfused myocardial-infarction.

- $T_{2}{ }^{*}$ imaging should be the preferred CMR method for assessment of intramyocardial haemorrhage.

- Intramyocardial haemorrhage can be considered as an important influencing factor on patient's outcome.

Keywords Cardiac magnetic resonance imaging - Acute myocardial infarction $\cdot$ Haemorrhage $\cdot$ Microvascular obstruction $\cdot$ Hypointense core

$\begin{array}{ll}\text { Abbreviations } \\ \text { 3D-IR-GRE } & \begin{array}{l}\text { 3D inversion recovery gradient echo } \\ \text { sequence }\end{array} \\ \text { AAR } & \begin{array}{l}\text { area at risk } \\ \text { cardiac magnetic resonance }\end{array} \\ \text { EDV } & \text { end-diastolic volume } \\ \text { ESV } & \text { end-systolic volume } \\ \text { Gd-DTPA } & \begin{array}{l}\text { gadolinium } \\ \text { diethylenetriaminepentaacetic acid }\end{array} \\ & \text { hypointense core } \\ \text { HIC } & \text { intramyocardial haemorrhage } \\ \text { IMH } & \text { late gadolinium enhancement }\end{array}$




$\begin{array}{ll}\text { LV } & \text { left ventricular } \\ \text { MSI } & \text { myocardial salvage index } \\ \text { MVO } & \text { microvascular obstruction } \\ \text { OR } & \text { odds ratio } \\ \text { PPCI } & \text { primary percutaneous coronary intervention } \\ \text { SA } & \text { short-axis } \\ \text { SSFP } & \text { steady state free precession } \\ \text { STEMI } & \text { ST-elevation myocardial infarction } \\ \text { T }_{2} \text {-STIR } & \mathrm{T}_{2} \text { short tau inversion recovery sequence } \\ \text { TIMI } & \text { thrombolysis in myocardial infarction } \\ \text { TE } & \text { echo time } \\ \text { TR } & \text { repetition time }\end{array}$

\section{Introduction}

Microvascular obstruction (MVO) and intramyocardial haemorrhage (IMH) are both frequent phenomena after reperfused ST-elevation myocardial infarction (STEMI) $[1,2]$ and partly represent reperfusion injury after primary percutaneous coronary intervention (PPCI) [3]. MVO or the so-called no-reflow phenomenon is caused by (1) embolization of particulate debris, (2) release of vasoconstrictor, thrombogenic and inflammatory substances, and (3) structural collapse of the capillary bed. MVO is associated with adverse ventricular remodelling and worse prognosis [4]. Equally, IMH is considered as severe damage after revascularization by PPCI or fibrinolysis which portends adverse prognosis [5]. Structural and functional degradation of the microcirculation causes extravasation of erythrocytes in the reperfused myocardium $[6,7]$. The pathophysiology of IMH is not fully understood yet and it remains unresolved if IMH is a consequence of MVO or vice versa and CMR and other imaging modalities might help to better understand that phenomenon [8-14]. However, previous studies demonstrated that IMH presence is an independent predictor of adverse left ventricular (LV) remodelling and associated with larger infarct size [15]. O'Regan et al. demonstrated a positive correlation between IMH and MVO and also IMH and infarct size in one of the first human "in vivo" cardiac magnetic resonance (CMR) studies using $\mathrm{T}_{2}{ }^{*}$-weighted images [16]. $\mathrm{T}_{2}{ }^{*}$-weighted CMR is a sensitive and potentially more specific technique for detecting IMH $[8,9]$. The $\mathrm{T}_{2}{ }^{*}$ sequence was originally used to illustrate cerebral haemorrhage $[17,18] . \mathrm{T}_{2}$-weighted CMR was utilized for quantifying oedema $[3,5]$, detecting the area at risk (AAR) and calculating the myocardial salvage [5,19-21]. In some cases a so-called hypointense core (HIC) could additionally be visualised within the increased signal intensity representing oedema. These regions of hypointense signal have been demonstrated to correspond to histological evidence of myocardial haemorrhage [8,9]. However, studies have also demonstrated that MVO may also cause hypointense infarct cores [22]. Consequently, it does not seem possible to differentiate if HIC illustrates MVO, IMH or both by using exclusively $\mathrm{T}_{2}$-weighted sequences. To examine the exact extent and prognostic impact of both findings as well as influencing factors, it is crucial to precisely distinguish between IMH and MVO.

The aim of this study was therefore to evaluate the performance of $\mathrm{T}_{2}{ }^{*}$ and HIC for detection of IMH and to assess the relationship between IMH and clinical as well as CMR markers of myocardial damage.

\section{Material and methods}

Patient population

A total of 151 consecutive patients (114 men, 37 women) undergoing PPCI for STEMI at a tertiary care centre were included between August 2009 and March 2010. All patients presented with typical chest pain within $12 \mathrm{~h}$ (Table 1) and had ST-segment elevation of $\geq 0.1 \mathrm{mV}$ in $\geq 2$ extremity leads or $\geq 0.2 \mathrm{mV}$ in $\geq 2$ precordial leads.

All patients gave written informed consent and the study was approved by the local ethics committee. This analysis is a substudy from the Abciximab Intracoronary versus intravenously Drug Application in STEMI (AIDA STEMI) trial (ClinicalTrial.gov Identifier NCT00712101) [23-25]. Exclusion criteria for this CMR substudy were claustrophobia, pregnancy, clinical instability, metallic implants, implanted pacemakers or defibrillators.

The patients were categorized into two groups defined by the presence or absence of IMH by using $\mathrm{T}_{2}{ }^{*}$ imaging. Furthermore, cardiovascular risk factors, reperfusion times, medication, culprit vessel, thrombolysis in myocardial infarction (TIMI) flow grade before and after PPCI as well as LV function and volumes were assessed to define possible influencing factors of IMH (Table 1). For culprit lesion identification, the three main vessels - left anterior descending artery, right coronary artery or left circumflex artery - were also assessed for proximal, mid or distal lesion location. The blood flow in the culprit vessel was graded according to the TIMI flow grade before and after PPCI: grade 0, no reperfusion; grade 1, low reperfusion; grade 2, partial reperfusion; and grade 3, regular perfusion [26].

\section{CMR imaging protocol}

CMR was performed on a 1.5-Tesla scanner (Intera, Philips Medical Systems, Best, the Netherlands) using a five-channel phased-array surface coil within 8 days after PPCI.

- First, for functional analysis standard steady state free precession (SSFP) sequences in breath-hold were 
Table 1 Patient characteristics

\begin{tabular}{|c|c|c|c|c|c|c|c|}
\hline & $\begin{array}{l}\text { All patients } \\
(n=151)\end{array}$ & $\begin{array}{l}\text { Haemorrhage present } \\
\text { in } \mathrm{T}_{2}^{*} \text { mapping } \\
(n=76)\end{array}$ & $\begin{array}{l}\text { Haemorrhage absent } \\
\text { in } \mathrm{T}_{2}^{*} \text { mapping } \\
(n=75)\end{array}$ & $\begin{array}{l}P \text { value univariate } \\
\text { analysis }\end{array}$ & $\begin{array}{l}X^{2} \text { univariate } \\
\text { analysis }\end{array}$ & $\begin{array}{l}\text { OR univariate } \\
\text { analysis }\end{array}$ & $95 \% \mathrm{CI}$ \\
\hline \multicolumn{8}{|l|}{ Variable } \\
\hline Age, years & $61(29-88)$ & $60(42-82)$ & $62(29-88)$ & 0.36 & 0.85 & 0.988 & $0.962-1.014$ \\
\hline Male, $n(\%)$ & $114(75)$ & $61(80)$ & $53(71)$ & 0.17 & 1.86 & 1.69 & $0.800-3.580$ \\
\hline Female, $n(\%)$ & $37(25)$ & $15(20)$ & $22(29)$ & & & & \\
\hline \multicolumn{8}{|l|}{ Cardiovascular risk factors, $n(\%)$} \\
\hline Current smoking & $81(54)$ & $44(59)$ & $37(49)$ & 0.29 & 1.11 & 1.41 & $0.743-2.680$ \\
\hline Arterial hypertension & $103(68)$ & $52(69)$ & $51(67)$ & 0.96 & 0.00 & 1.02 & $0.514-2.020$ \\
\hline Hypercholesterolaemia & $52(34)$ & $20(27)$ & $32(43)$ & 0.03 & 4.40 & 0.480 & $0.242-0.953$ \\
\hline Diabetes mellitus & $32(21)$ & $18(24)$ & $14(19)$ & 0.45 & 0.57 & 1.35 & $0.620-2.970$ \\
\hline Obesity & $100(66)$ & $47(62)$ & $53(71)$ & 0.28 & 1.17 & 0.674 & $0.330-1.380$ \\
\hline $\begin{array}{l}\text { Positive medical family } \\
\text { history of CAD }\end{array}$ & $52(34)$ & $30(40)$ & $22(29)$ & 0.19 & 1.71 & 1.57 & $0.800-3.090$ \\
\hline Stroke & $1(0.7)$ & $0(0)$ & $1(1.3)$ & 0.49 & 0.00 & 0.00 & \\
\hline BMI, $\mathrm{kg} / \mathrm{m}^{2}$ & $28.3 \pm 4$ & $27.9 \pm 5$ & $28.7 \pm 4$ & 0.28 & 1.33 & 0.955 & $0.883-1.030$ \\
\hline \multicolumn{8}{|l|}{ Reperfusion times, min } \\
\hline Pain-to-balloon time & $263 \pm 196$ & $281 \pm 194$ & $245 \pm 198$ & 0.26 & 0.27 & 1.01 & $0.982-1.030$ \\
\hline Door-to-balloon time & $30 \pm 13$ & $31 \pm 13$ & $30 \pm 14$ & 0.61 & 1.23 & 1.00 & $1.000-1.000$ \\
\hline \multicolumn{8}{|l|}{ Culprit vessel } \\
\hline LAD (proximal/mid/distal) & $64(29 / 31 / 4)$ & $38(19 / 17 / 2)$ & $26(10 / 14 / 2)$ & 0.06 & 4.03 & 2.450 & $1.020-5.880$ \\
\hline RCA (proximal/mid/distal) & $59(28 / 13 / 18)$ & $22(8 / 7 / 7)$ & $37(20 / 6 / 11)$ & 0.01 & 7.31 & 0.281 & $0.112-0.706$ \\
\hline LCX (proximal/mid/distal) & $28(5 / 20 / 3)$ & $16(3 / 11 / 2)$ & $12(2 / 9 / 1)$ & 0.42 & 0.24 & 1.570 & $0.254-9.760$ \\
\hline $\begin{array}{l}\text { TIMI flow grade before PPCI } \\
\leq 1, n(\%)\end{array}$ & $92(61)$ & $54(71)$ & $38(51)$ & 0.02 & 5.26 & 2.23 & $1.120-4.440$ \\
\hline $\begin{array}{l}\text { TIMI flow grade after PPCI } \\
\quad<3, n(\%)\end{array}$ & $16(11)$ & $6(8)$ & $10(13)$ & 0.55 & 1.28 & 0.540 & $0.186-1.570$ \\
\hline \multicolumn{8}{|l|}{ Medication, $n(\%)$} \\
\hline Beta-blocker & $38(25)$ & $26(34)$ & $12(16)$ & 0.01 & 6.40 & 2.730 & $1.250-5.950$ \\
\hline ACE inhibitor & $25(17)$ & $11(15)$ & $14(19)$ & 0.49 & 0.48 & 0.737 & $0.311-1.750$ \\
\hline AT-1 antagonist & $22(15)$ & $9(12)$ & $13(17)$ & 0.34 & 0.91 & 0.641 & $0.256-1.600$ \\
\hline Acetylsalicylic acid (ASA) & $32(21)$ & $18(24)$ & $14(19)$ & 0.45 & 0.57 & 1.350 & $0.616-2.970$ \\
\hline Clopidogrel & $10(7)$ & $6(8)$ & $4(5)$ & 0.75 & 0.40 & 1.520 & $0.412-5.620$ \\
\hline Statin & $24(16)$ & $11(15)$ & $13(17)$ & 0.63 & 0.23 & 0.810 & $0.336-1.940$ \\
\hline \multicolumn{8}{|c|}{ Hours between PPCI and CMR, $n(\%)$} \\
\hline $12-72 \mathrm{~h}$ & $110(73)$ & $51(67)$ & $59(79)$ & 0.11 & 3.33 & 1.25 & $0.984-1.590$ \\
\hline$>72 \mathrm{~h}$ & $41(27)$ & $25(33)$ & $16(21)$ & & & & \\
\hline
\end{tabular}

Data are reported as mean $\pm \mathrm{SD}$ or mean (minimum-maximum) if continuous and number (percentage) if categorical

$O R$ odds ratio, $C I$ confidence interval

obtained in four- and two-chamber view and a stack of short-axis slices to cover the whole LV as described previously [27-29]. The scan parameters were as follows: repetition time $(\mathrm{TR})=3.6 \mathrm{~ms}$, echo time $(\mathrm{TE})=1.8 \mathrm{~ms}$, flip angle $=60^{\circ}$, slice thickness $=8 \mathrm{~mm}$, maximum field of view $(\mathrm{FOV})=400 \mathrm{~mm}$, matrix $256 \times 256$, in-plane resolution $<1.56 \times 1.56 \times 8 \mathrm{~mm}$.

- Second, a stack of short-axis slices covering the whole $\mathrm{LV}$ using a black blood $\mathrm{T}_{2}$-weighted short tau inversion recovery $\left(\mathrm{T}_{2}\right.$-STIR) sequence $(\mathrm{TR}=2 \mathrm{RR}$ intervals, $\mathrm{TE}=80 \mathrm{~ms}$, flip angle $=90^{\circ}$, slice thickness $=10 \mathrm{~mm}$, maximum field of view $(\mathrm{FOV})=370 \mathrm{~mm}$, matrix $512 \times 512$, in-plane resolution $<0.72 \times 0.72 \times 10 \mathrm{~mm}$ ) were acquired for detecting HIC within myocardial oedema (Figs. 1a, 2a) and the area at risk (AAR) by a free-breathing navigator technique.

- Third, the same slice orientation as for the $\mathrm{T}_{2}$-STIR image was chosen for IMH detection in the middle of the myocardial oedema, centrally located within the "area at risk" of myocardial infarction (Figs. 1a, 2a). The $\mathrm{T}_{2}{ }^{*}$ sequence with the following parameters was used: $\mathrm{TR}=$ $17 \mathrm{~ms}, \mathrm{TE}=1,3,6,8,10,12,15 \mathrm{~ms}$, flip angle $=$ 
Fig. 1 IMH with MVO and HIC: Short-axis CMR images obtained 2 days after ischemic reperfusion injury (pain-to-balloon time $523 \mathrm{~min}$ ) in a 53 -yearold man. In the anteroseptal myocardium a large transmural hyperintense region and HIC directly centrally located therein (white arrows) are present on the $\mathrm{T}_{2}$-STIR image (a); also, a major hyperintense, contrast-enhancing region (necrosis) with a clear MVO (white arrows) within can be visualised on the LGE image (b) and a huge haemorrhage indicated by a hypointense signal (white arrows) can be seen on the $\mathrm{T}_{2}{ }^{*}$-weighted image at a TE of $15 \mathrm{~ms}(\mathbf{c})$ and within the $\mathrm{T}_{2}{ }^{*}-$ weighted parameter image indicating a $T_{2}{ }^{*}$-decay $\leq 20 \mathrm{~ms}(\mathbf{d})$, the threshold for haemorrhage in this study [16]

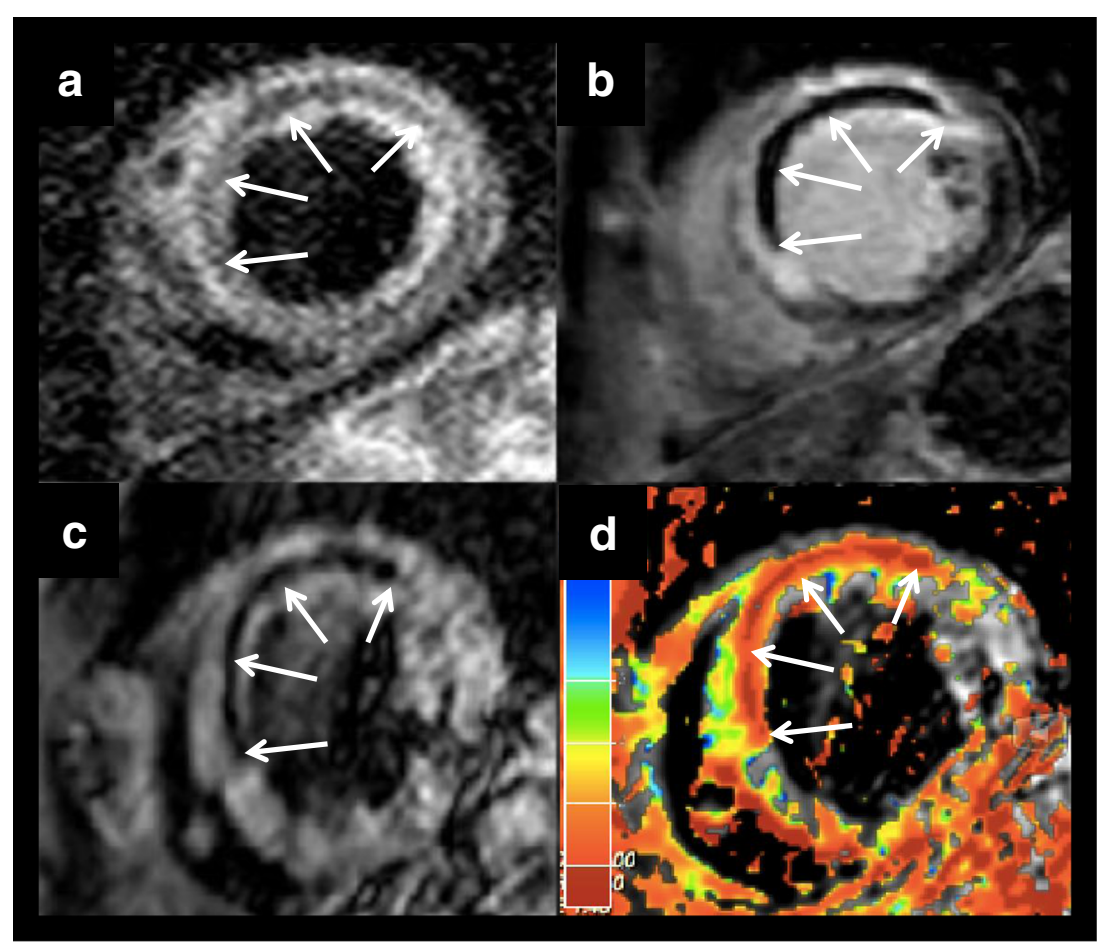

$20^{\circ}$, slice thickness $=10 \mathrm{~mm}$, maximum field of view $(\mathrm{FOV})=240 \mathrm{~mm}$, matrix $256 \times 256$, in-plane resolution
$<0.94 \times 0.94 \times 10 \mathrm{~mm}$. Images at seven different TE

(Figs. 1c, 2c) to calculate relaxation curves, a parameter
Fig. 2 IMH without MVO and HIC: Short axis CMR images obtained 3 days after ischemic reperfusion injury (pain-toballoon time $126 \mathrm{~min}$ ) in a 74-year-old woman with an occlusion of the circumflex artery (LCX). a Demonstrates an oedema in the inferior wall without a HIC, b the LGE in the inferior wall without any MVO and $\mathbf{c}$ an obvious haemorrhage (white arrows) on the $\mathrm{T}_{2}{ }^{*}$ weighted image at a TE of $15 \mathrm{~ms}$ and within the $\mathrm{T}_{2}{ }^{*}$-weighted parameter image indicating a $\mathrm{T}_{2}{ }^{*}$ decay $\leq 20 \mathrm{~ms}$, $\mathbf{d}$ the threshold for haemorrhage in this study [16]

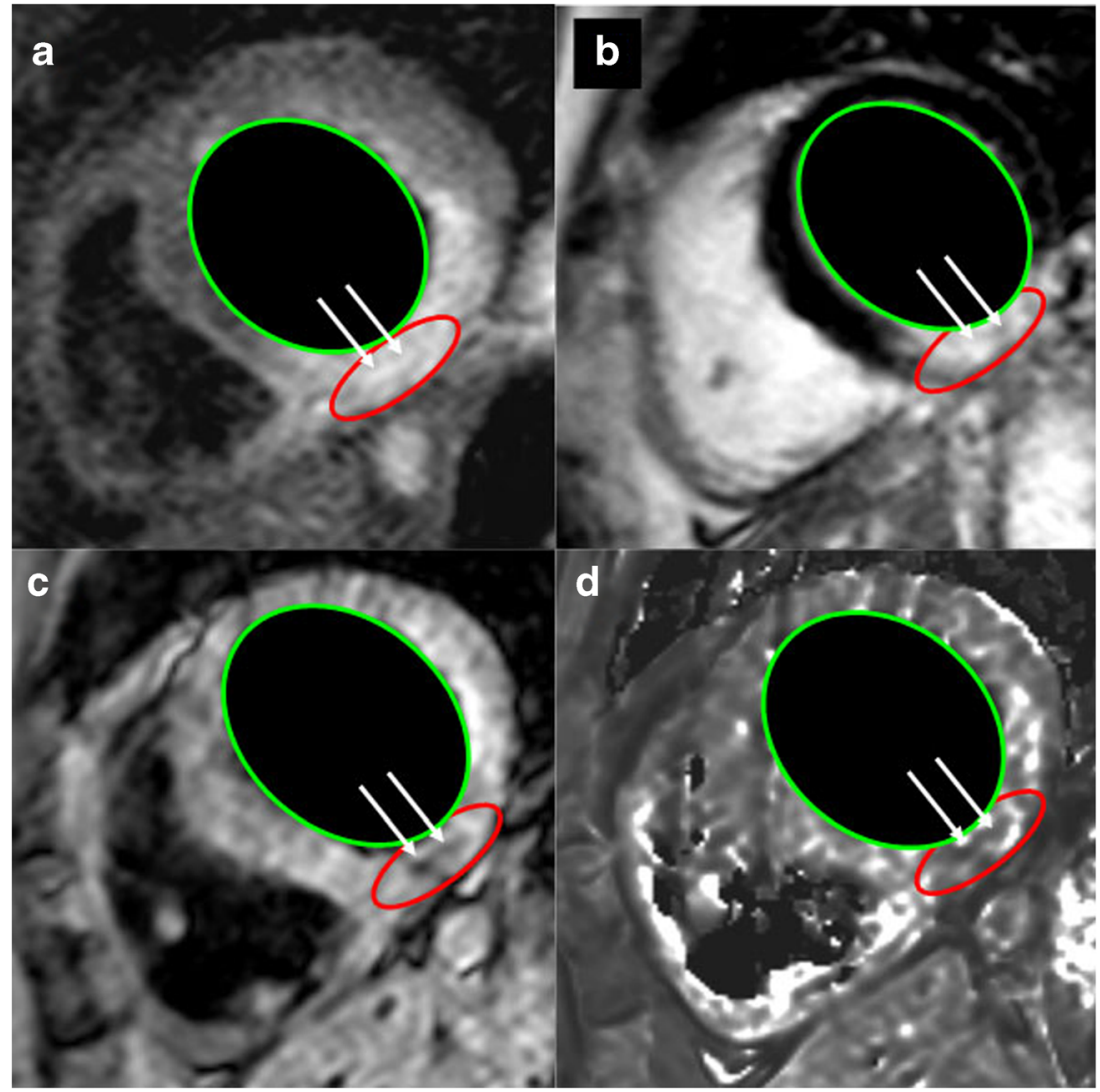


image (Figs. 1d, 2d) and the $\mathrm{T}_{2}{ }^{*}$ decay [16] were obtained from the parameter images. The occurrence or absence of HIC with or without IMH was documented.

- Fourth and finally, late gadolinium enhancement (LGE) images (Figs. 1b, 2b), sensitive for necrosis and MVO, were acquired 10-15 min after intravenous administration of $0.15 \mathrm{mmol} / \mathrm{kg}$ Gd-DTPA by using a 3D-inversion recovery gradient echo sequence (IR-GRE) with the following parameters: $\mathrm{TR}=2.9 \mathrm{~ms}, \mathrm{TE}=1.5 \mathrm{~ms}$, flip angle $=$ $15^{\circ}$, slice thickness $=10 \mathrm{~mm}(5 \mathrm{~mm}$ increment $)$, maximum field of view $(F O V)=370 \mathrm{~mm}$, matrix $280 \times 280$, in-plane resolution $<1.32 \times 1.32 \times 10 \mathrm{~mm}$.

\section{CMR image analysis}

All images were analysed using a dedicated workstation (ViewForum R4.2V1C2 SP1, Software Release 2005-11-04, Philips Medical Systems, Best, the Netherlands). LV volumes and function for every patient were assessed by manually outlining the endocardial contours of the LV from the SSFP short axes sequences [5]. Short-axis $\mathrm{T}_{2}$-STIR sequences were used to detect and to assess oedema and HIC (Figs. 1a, 2a). In the LGE images the size of myocardial infarction was measured by using a threshold of two standard deviations of the remote myocardium $[5,27]$. In addition, the presence or absence of MVO was documented (Figs. 1b, 2b). The salvaged myocardium after PPCI was expressed by the myocardial salvage index (MSI) calculated from the difference between oedema and necrosis divided by oedema [21]. IMH was considered as the region with decreased signal intensity in the $\mathrm{T}_{2}{ }^{*}$-weighted images based on the paramagnetic effects of deoxyhaemoglobin and the reduction of the $\mathrm{T}_{2}$ time [30]. The used sequence provided $\mathrm{T}_{2}{ }^{*}$-weighted images with the described different TE additionally to a parameter image, which was used to calculate the $\mathrm{T}_{2}{ }^{*}$ decay. According to previous publications a decay at the $\mathrm{T}_{2}{ }^{*}$ parameter image $\leq 20 \mathrm{~ms}$ was considered as positive haemorrhage [16] (Figs. 1d, 2d).

\section{Statistical analysis}

The study cohort was characterized by mean \pm standard deviation (SD) for continuous variables and by absolute and relative frequencies for categorical variables. Continuous variables were compared within the group of patients with and without IMH by Student's $t$ test. Proportions were compared by Pearson's $\chi^{2}$ test (Tables 1,3 ) and Fisher's exact test where appropriate.

Furthermore, a stepwise logistic regression analysis was applied to identify possible predictors of the occurrence of IMH. All statistically significant clinical and CMR variables of the univariate analyses (Tables 1, 3) were included in the final multivariable model. All variables selected by this algorithm were included in a final model in order to get odds ratio estimates with the corresponding $95 \%$ confidence intervals (Table 4). All tests performed were two-sided with a significance level of $5 \%$. All statistical analyses were done by means of SPSS software, version 16.0 for Windows.

\section{Results}

CMR was performed at a mean of 2.8 days (range $0-8$ days) after PPCI. The mean patient age of the 76 patients with IMH was $60 \pm 11$ years. There were no significant differences between patients with or without IMH concerning common patient characteristics except for hypercholesterolaemia (Table 1).

Functional and volumetric assessment

LV ejection fraction was significantly lower in patients with IMH compared to those without ( $43.5 \pm 9.7 \%$ vs. $51.1 \pm 8.6 \%$, $P<0.001$ ) (Fig. 3). Patients with IMH also had a higher LVEDV $(163 \pm 40 \mathrm{ml}$ vs. $145 \pm 30 \mathrm{ml}, P<0.01)$ and LV-ESV $(94 \pm 36 \mathrm{ml}$ vs. $72 \pm 23 \mathrm{ml}, P<0.001)$.

Comparison of $\mathrm{T}_{2}{ }^{*}$ mapping and $\mathrm{T}_{2}$-weighted imaging for IMH detection

By using $\mathrm{T}_{2}{ }^{*}$ mapping IMH was detected in $50 \%$ of all patients (76/151). $\mathrm{T}_{2}$-weighted STIR images demonstrated HIC in $54 \%$ $(82 / 151)$ and LGE images demonstrated MVO in $66 \%(100 / 151)$ of all patients (Fig. 4).

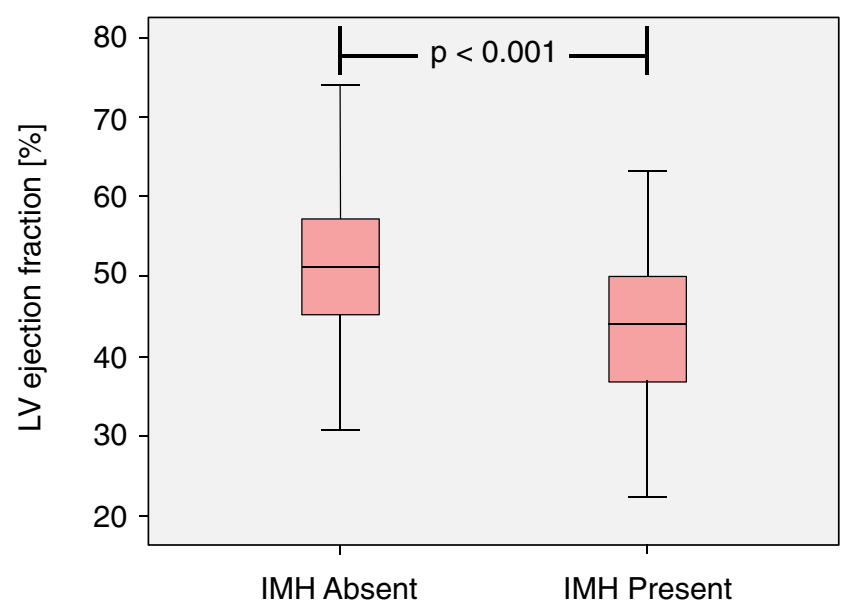

Fig. 3 Relationship between LV ejection fraction and haemorrhage. Patients with IMH had a significantly lower LV-EF than those without IMH (43.5 $\pm 9.7 \%$ vs. $51.1 \pm 8.6 \%, P<0.001)$ 
IMH occurred in the majority of patients (95\%; 72/ 76) concomitantly with MVO (Fig. 1) and in only $5 \%$ (4/76) without (Fig. 2). When IMH and MVO were present at the same time IMH occurred in centre areas of the MVO. This phenomenon was observed especially in large infarcts with large MVO areas. Additionally, two of these four patients showed neither HIC nor a concomitant MVO. HIC occurred in $6 \%(5 / 82)$ of patients without MVO.

Eighty-four percent (64/76) of patients with IMH showed HIC in $\mathrm{T}_{2}$-STIR images (Table 2), whereas in $16 \%(12 / 76)$ of patients IMH was not accompanied by HIC.

Influencing factors for IMH occurrence

Differences could be demonstrated related to potential influencing factors for the occurrence of IMH. The following factors were analysed:

\section{Location of occlusion}

In $42 \%(64 / 151)$ of patients the LAD, in $39 \%(59 / 151)$ the RCA and in $18.5 \%(28 / 151)$ the LCX was occluded. The culprit vessel in the majority of patients with IMH was the

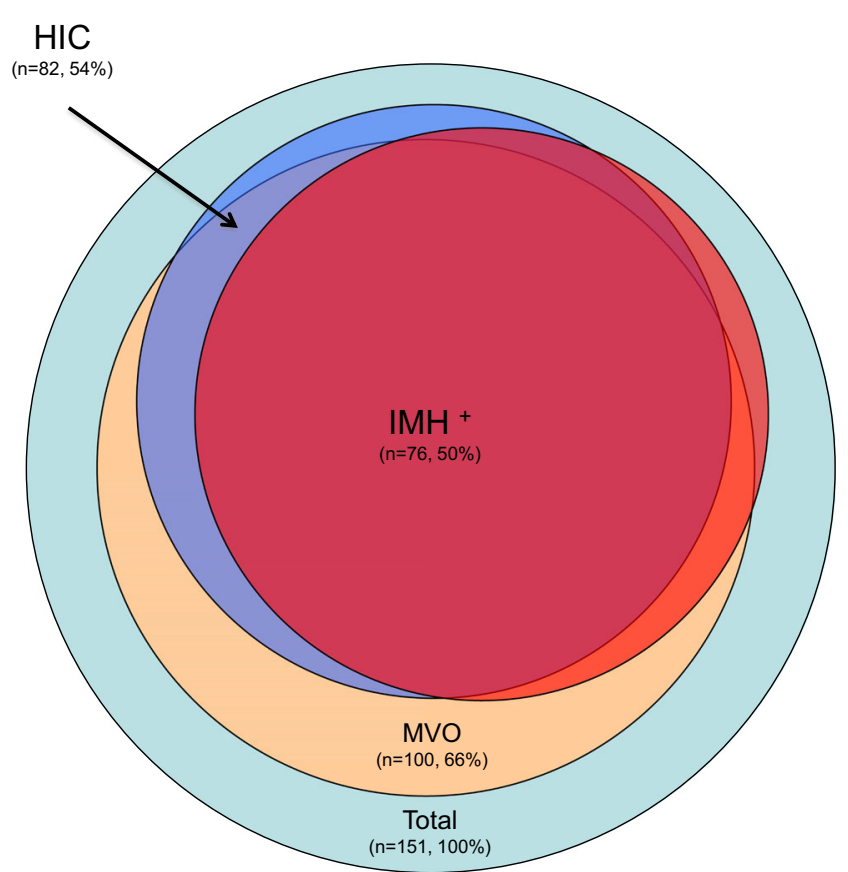

Fig. 4 Venn diagram of the frequency of IMH, MVO and HIC out of the basic population. It demonstrates the occurrence of IMH without MVO and/or HIC. CMR cardiovascular magnetic resonance, IMH intramyocardial haemorrhage, $M V O$ microvascular obstruction, $H I C$ hypointense core in $\mathrm{T}_{2}$-STIR
LAD (50\% vs. $35 \%, P=0.06)$ and without IMH was the RCA ( $29 \%$ vs. $49 \%, P=0.01$ ) (Table 1$)$.

\section{TIMI flow before PPCI}

In $\mathrm{IMH}^{+}$patients a TIMI flow $\leq 1$ before PPCI was significantly more frequent than in $\mathrm{IMH}^{-}$patients $(72 \%$ vs. $54 \%$, $P<0.001$ ) (Fig. 5).

\section{Medication}

A statistically significant difference in premedication of the $\mathrm{IMH}^{+}$vs. $\mathrm{IMH}^{-}$group could only be demonstrated with regard to the intake of beta-blockers (34\% vs. $16 \%$; $P=0.01$ ) (Table 1). All other premedication, like angiotensin-1 antagonists, ACE inhibitors or the intake of acetylsalicylic acid (ASA), clopidogrel or statins were not significantly different in both groups.

Infarct size/myocardial salvage index (MSI)

$\mathrm{IMH}^{+}$patients had significantly larger infarcts $(32.6 \pm 20.3 \mathrm{ml}$ vs. $12.9 \pm 9.5 \mathrm{ml}, P<0.001)$ (Fig. 6$)$ and a lower MSI (36 \% $21 \%$ vs. $59 \% \pm 25 \%, P<0.001$ ) (Fig. 7).

\section{Predictors of IMH}

A stepwise logistic regression model was applied to identify possible predictors of the occurrence of IMH (Tables 1, 3). After the use of a univariate analysis several significant parameters were left for the multivariate analysis, like TIMI flow grade before PPCI $\leq 1$ or the MSI. Nevertheless, the final multivariate analysis revealed that patients with a HIC, or even more likely with the presence of MVO, demonstrated a high OR for the occurrence of IMH (Table 4). These results again demonstrate the close relation between $\mathrm{HIC}$ and MVO and the frequent appearance of both phenomena together with IMH. Surprisingly, an intake of beta-blockers demonstrated the highest OR for the occurrence of IMH. However, there was neither a significant difference between $\mathrm{IMH}^{+}$ and $\mathrm{IMH}^{-}$patients according to the presence of arterial hypertension, nor a tendency toward higher systolic or diastolic blood pressure in the $\mathrm{IMH}^{+}$group. However, in the $\mathrm{IMH}^{+}$group more patients were on a combined antihypertensive drug therapy with beta-blockers as compared to the $\mathrm{IMH}^{-}$group.

\section{Discussion}

In our large study $(n=151)$ we could demonstrate the importance of using dedicated $\mathrm{T}_{2}{ }^{*}$-weighted CMR sequences to 
Table 2 Differences in the detection of $\mathrm{HIC}$ and $\mathrm{MVO}$ in $\mathrm{IMH}^{+}$versus $\mathrm{IMH}^{-}$patients
Data are reported as number (percentage)

+ present, - absent

\begin{tabular}{llll}
\hline & $\begin{array}{l}\text { Haemorrhage present } \\
\text { in } \mathrm{T}_{2}^{*} \text { mapping } \\
(n=76)\end{array}$ & $\begin{array}{l}\text { Haemorrhage absent } \\
\text { in } \mathrm{T}_{2}^{*} \text { mapping } \\
(n=75)\end{array}$ & $P$ value \\
\hline $\mathrm{HIC}^{+}$(STIR), $n(\%)$ & $64(84)$ & $18(24)$ & $<0.001$ \\
$\mathrm{HIC}^{-}$(STIR), $n(\%)$ & $12(16)$ & $57(76)$ & $<0.001$ \\
$\mathrm{MVO}^{+}$(3D-IR-GRE), $n(\%)$ & $72(95)$ & $28(37)$ & $<0.001$ \\
$\mathrm{MVO}^{-}$(3D-IR-GRE), $n(\%)$ & $4(5)$ & $47(63)$ & $<0.001$ \\
\hline
\end{tabular}

detect IMH after acute reperfused STEMI to definitely distinguish IMH from MVO. In some cases IMH could be detected even without a visible MVO (Fig. 2), which is in contrast to several other studies $[5,6,11,31,32]$. Our data indicate that $\mathrm{T}_{2}$-STIR sequences only, which are generally used to visualise AAR and MSI, are not able to reliably detect IMH as a HIC within the oedema. Furthermore, potential influencing factors for the occurrence of IMH could be evaluated.

Our most important findings can be summarized as follows:

1. IMH is a common finding in patients with acute STEMI after PPCI and was present in approximately $50 \%$ of our patients.

2. Our data demonstrated that the majority of $\mathrm{T}_{2}{ }^{*}$ defects were also defects on $T_{2}$ imaging (HIC), but some $T_{2}$ defects had had no defect on $\mathrm{T}_{2}{ }^{*}$ imaging. Although not directly proven by our works, experimental studies suggest [33-36] that $\mathrm{T}_{2}{ }^{*}$ imaging is more accurate for IMH than $\mathrm{T}_{2}$ imaging and therefore should be the preferred technique for detection of IMH.

3. However, according to the multivariate analysis $\mathrm{HIC}$ on $\mathrm{T}_{2}$ imaging and MVO on LGE images are highly correlated with occurrence of defect on $\mathrm{T}_{2}{ }^{*}$ images indicating IMH.

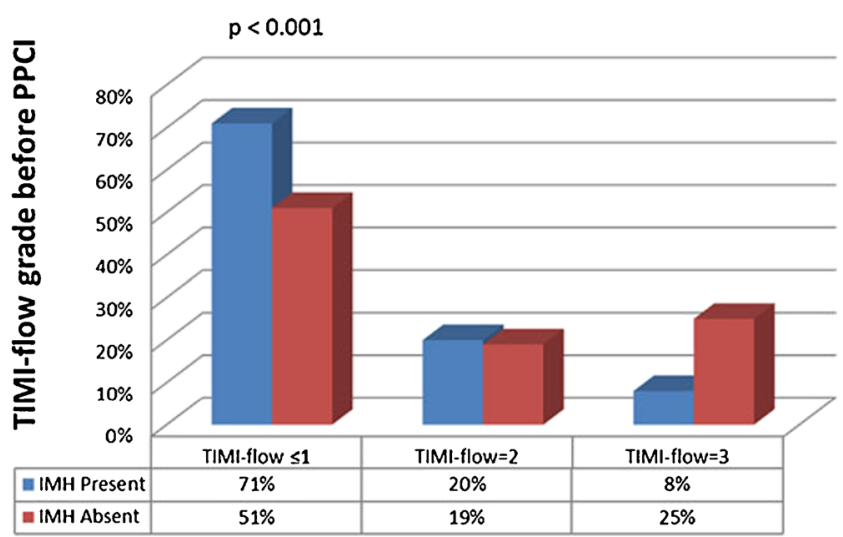

Fig. 5 Relationship between TIMI flow before PPCI $\leq 1$ and haemorrhage: In $\mathrm{IMH}^{+}$patients a TIMI flow $\leq 1$ before PPCI was significantly more frequent than in $\mathrm{IMH}^{-}$patients ( $71 \%$ vs. $51 \%, P<0.001$ ), which could be considered as a potential influencing factor for the development of IMH
CMR after reperfused STEMI and the role of the used sequences

CMR is considered as the gold standard for the assessment of ventricular volumes and mass [28, 37] as well as in patients with acute reperfused myocardial infarction as the preferred method for the noninvasive evaluation of viability, infarct size and myocardial salvage with a high prognostic value $[5,38$, 39]. The prognostic value of MVO and IMH after acute reperfused myocardial infarction has previously been described [5, 11, 16]. However, there is disagreement in the literature about the best CMR sequences to detect IMH $[5,7,10,11,15,30,33-36,38,40,41]$ and how to definitely differentiate it from MVO.

Pedersen et al. demonstrated in an animal study that $\mathrm{T}_{1^{-}}$ weighted sequences are more accurate than $\mathrm{T}_{2}$ - or $\mathrm{T}_{2}{ }^{*}$-weighted sequences for the detection of IMH [40]. In contrast to this study Bradley and Kali et al. [17, 34] showed the highest sensitivity for IMH detection by using $\mathrm{T}_{2}{ }^{*}$-weighted CMR sequences, which is in line with previous data in neuroradiology $[17,18,42]$ and animal models using $\mathrm{T}_{2}{ }^{*}$ mapping in the heart [10]. Lotan et al. declared difficulties in the detection of

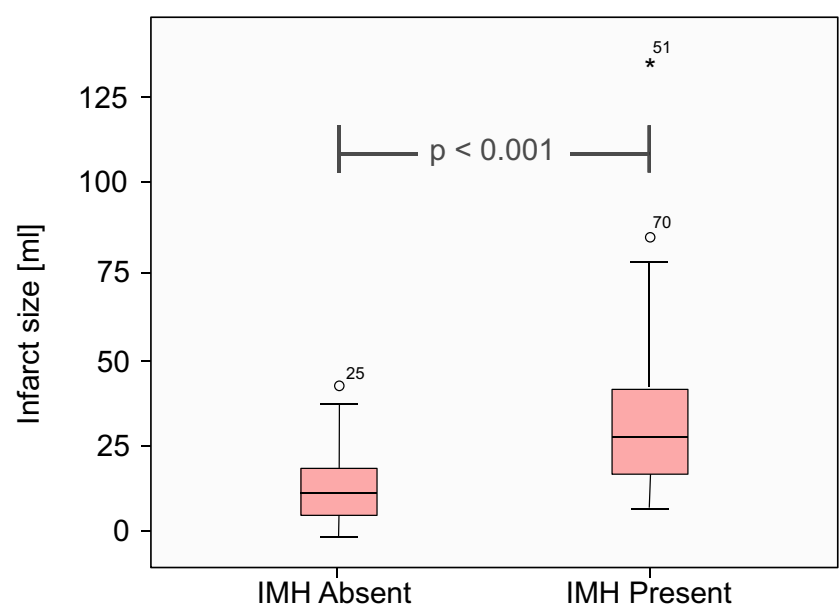

Fig. 6 Relationship between infarct size and haemorrhage: the IMH group had significantly larger mean infarct sizes $(32.6 \pm 20.3 \mathrm{ml}$ vs. $12.9 \pm 9.5 \mathrm{ml}, P<0.001)$ at the LGE sequences 


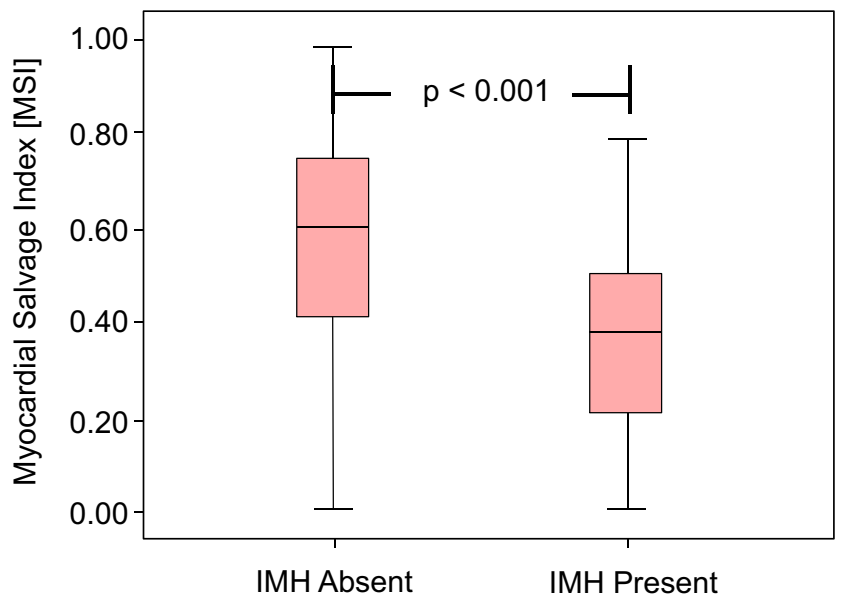

Fig. 7 Relationship between myocardial salvage index and haemorrhage. MSI in the IMH group was significantly lower than in the nonIMH group $(0.36 \pm 0.21$ vs. $0.59 \pm 0.25, P<0.001)$

haemorrhage by using $\mathrm{T}_{2}$-weighted images only. That study group stated that the reciprocal influencing effects of the hyperintense oedema and HIC may mask IMH [31]. Furthermore, a postmortem study by Jackowski et al. [35] demonstrated that MVO without haemorrhage and $\mathrm{HIC}$ on $\mathrm{T}_{2^{-}}$ weighted images exist.

Nevertheless, there is a strong relationship between the occurrence of IMH and MVO [41]. Also this study demonstrated MVO in $95 \%$ of patients with IMH.

But it has also been described before that some patients may exclusively present IMH or MVO [38]. In the current study $5 \%$ of patients with IMH did not show any MVO. Therefore, we suppose that $\mathrm{T}_{2}{ }^{*}$-weighted sequences could detect small amounts of haemorrhage with a very high
Table 4 Characteristics associated with IMH/predictors of IMH

\begin{tabular}{llc}
\hline Variable & Odds ratio $(95 \% \mathrm{CI})$ & $P$ value multivariate \\
\hline Volume of MVO $(\mathrm{ml})$ & $4.1(1.4-12.3)$ & 0.01 \\
Volume of HIC $(\mathrm{ml})$ & $2.9(1.8-4.8)$ & $<0.001$ \\
Beta-blocker at admission & $4.6(1.6-13.1)$ & 0.004
\end{tabular}

sensitivity, despite a slightly lower spatial resolution as compared to the $\mathrm{T}_{2}$-STIR, but also only slightly higher than the LGE sequences.

However, in previous studies and also in our study it could not definitely be clarified if IMH can be present without MVO and further studies are still needed to examine this finding. Prior analysis had demonstrated that $\mathrm{T}_{2}{ }^{*}$-weighted sequences in particular can reliably detect even small amounts of cerebral haemorrhage $[18,42,43]$. But the spatial resolution of the presently used LGE sequences may not be high enough to depict every $\mathrm{MVO}$, while the corresponding $\mathrm{T}_{2}{ }^{*}$-weighted sequences do for the detection of IMH. The spatial resolution of the $\mathrm{T}_{2}{ }^{*}$ sequence in our study was slightly higher than the spatial resolution of the LGE sequence.

Nevertheless, artefacts are common on $\mathrm{T}_{2}{ }^{*}$-weighted images and could mimic IMH. To reduce this potential source of misinterpretation a hypointense signal on the $\mathrm{T}_{2}{ }^{*}$ images was only defined as IMH if the decay on the parameter image was at most $20 \mathrm{~ms}$ as previously described [16]. In another study an even more sensitive threshold with a $\mathrm{T}_{2}{ }^{*}$ decay of less than $30 \mathrm{~ms}$ was proposed [32], which may additionally increase the number of $\mathrm{IMH}^{+}$patients without any visible MVO or HIC.

The occurrence of IMH without MVO on the LGE images may also be caused by passive diffusion of contrast agent into

Table 3 CMR results

\begin{tabular}{|c|c|c|c|c|c|c|c|}
\hline & $\begin{array}{l}\text { All patients } \\
(n=151)\end{array}$ & $\begin{array}{l}\text { Haemorrhage present } \\
\text { in } \mathrm{T}_{2}^{*} \text { mapping } \\
(n=76)\end{array}$ & $\begin{array}{l}\text { Haemorrhage absent } \\
\text { in } \mathrm{T}_{2}^{*} \text { mapping } \\
(n=75)\end{array}$ & $\begin{array}{l}P \text { value } \\
\text { univariate } \\
\text { analysis }\end{array}$ & $\begin{array}{l}X^{2} \text { univariate } \\
\text { analysis }\end{array}$ & $\begin{array}{l}\text { OR univariate } \\
\text { analysis }\end{array}$ & $95 \% \mathrm{CI}$ \\
\hline \multicolumn{8}{|l|}{ Variable } \\
\hline LV ejection fraction (\%) & $47 \pm 10$ & $43 \pm 10$ & $51 \pm 9$ & $<0.001$ & 19.6 & 0.912 & $0.876-0.950$ \\
\hline LV end-diastolic volume, $\mathrm{ml}$ & $154 \pm 37$ & $163 \pm 40$ & $145 \pm 30$ & 0.003 & 8.2 & 1.01 & $1.000-1.020$ \\
\hline LV end-systolic volume, $\mathrm{ml}$ & $83 \pm 32$ & $94 \pm 36$ & $72 \pm 23$ & $<0.001$ & 15.5 & 1.03 & $1.010-1.040$ \\
\hline LV stroke volume, $\mathrm{ml}$ & $71 \pm 16$ & $69 \pm 15$ & $73 \pm 15$ & 0.07 & 3.2 & 0.981 & $0.960-1.002$ \\
\hline Infarct size absolute, $\mathrm{ml}$ & $23 \pm 19$ & $33 \pm 20$ & $13 \pm 9$ & $<0.001$ & 33.5 & 1.13 & $1.080-1.170$ \\
\hline Myocardial salvage index (MSI) & $0.47 \pm 0.26$ & $0.36 \pm 0.21$ & $0.59 \pm 0.25$ & $<0.001$ & 25.2 & 0.014 & $0.003-0.073$ \\
\hline Volume of HIC at STIR, ml & $2.3 \pm 4.3$ & $4.2 \pm 5.4$ & $0.3 \pm 0.8$ & $<0.01$ & 9.18 & 4.67 & $1.730-12.90$ \\
\hline HIC at STIR, $n(\%)$ & $82(54)$ & $64(84)$ & $18(24)$ & $<0.001$ & & & \\
\hline Volume of MVO at 3D-IR-GRE, ml & $3.1 \pm 6.5$ & $5.8 \pm 8.3$ & $0.4 \pm 0.9$ & $<0.001$ & 27.7 & 3.62 & $2.240-5.850$ \\
\hline MVO present at 3D-IR-GRE, $n(\%)$ & $100(66)$ & $72(95)$ & $28(37)$ & $<0.001$ & & & \\
\hline
\end{tabular}

Data are reported as mean $\pm \mathrm{SD}$ or mean (minimum-maximum) if continuous and number (percentage) if categorical

$O R$ odds ratio, $C I$ confidence interval 
the small infarct core, obscuring the presence of MVO on the LGE images [44].

Furthermore, it is not yet understood what a $\mathrm{HIC}$ in $\mathrm{T}_{2}-$ weighted STIR sequences represents when IMH and MVO could not be demonstrated ( $2 \%(3 / 151)$ of all patients in this study). In one of only a few histologically confirmed postmortem analyses [35] HIC always represented MVO with or without IMH.

\section{Relationship between IMH and potential influencing factors}

Previous publications and this study confirmed that IMH is not always detectable in patients after acute reperfused STEMI. In about half of our patients IMH was detectable, which is consistent with findings from Beek et al. with $49 \%$ of patients with IMH [3] or Robbers et al. with $60 \%$ [44], but much more frequent as described in other studies [5, 45]. Therefore, potentially influencing factors for the occurrence of IMH should be evaluated. In our study most patients with IMH showed an occluded LAD (50\%) and patients without IMH presented more often an occluded RCA, which had already been described by Amabile et al. [45]. The majority of our patients ( $42 \%)$ had their culprit lesion in the LAD territory (Table 1) and the $\mathrm{IMH}^{+}$mostly in the proximal segment ( $50 \%$ vs. $38 \%$ ), whereas in the LCX it was mainly located at the middle segment, with an equal distribution within both groups. The second most involved territory was the RCA region (39\%), in which the $\mathrm{IMH}^{+}$demonstrated an almost equal distribution of proximally and distally located lesions. But in the $\mathrm{IMH}^{-}$group the culprit lesion was mainly located proximally in more than $50 \%$ of patients. Infarct size roughly correlates with the location of the culprit lesion and a proximal lesion in the LAD territory causes usually larger infarcts than a proximal lesion in the RCA. Furthermore, IMH correlated significantly with infarct size.

Patients with a low TIMI flow before PPCI $(\leq 1)$ seem to have a higher risk for the development of IMH (Fig. 5). Seventy-two per cent of our patients with a TIMI flow grade $\leq 1$ demonstrated an IMH, which was significantly different to those patients without IMH. Similar results could be demonstrated in prior studies, e.g. Eitel et al. reported on $87 \%$ patients with a TIMI flow grade $\leq 1$ before PPCI [5] and a HIC, which was used as an indicator for IMH in this study. Nevertheless, in the final multivariate analysis (Table 4) only HIC and especially MVO were significant predictors of IMH. Furthermore, the beta-blocker intake at admission was a strong predictor of IMH in patients. In the $\mathrm{IMH}^{+}$group more patients were on a combined antihypertensive therapy indicating a potentially more severe arterial hypertension, but this is rather speculative and has to be proven using another study design. However, several large trials on the use of betablockers in myocardial infarction demonstrated that the use of beta-blockers reduced the risks of reinfarction and ventricular fibrillation, but increased the risk of cardiogenic shock $[46,47]$. These findings changed the clinical practice of beta-blocker use in patients presenting with acute coronary syndromes, emphasizing the potential harm of beta-blockers in patients at increased risk of cardiogenic shock. Nevertheless, this unexpected finding may also be an epiphenomenon.

Relationship between IMH and ventricular function

Other studies have already demonstrated the relationship between the presence of IMH and significantly larger infarct sizes, decreased left ventricular function, less myocardial salvage and an adverse prognosis $[3,5,11]$. IMH after STEMI is seen as a reperfusion injury and closely related to larger infarct sizes [5]. In this study we confirmed a significantly lower LVEF, larger LV-EDV and LV-ESV and larger infarct sizes in patients with IMH. These findings were also seen in studies by Eitel et al. and Beek et al. [3, 5, 44]. Beek et al. did not find any prognostic influence of MVO [3]. O'Regan et al. supposed that the occurrence of IMH is related to a reduced myocardial salvage [16]. In our patients a significant impact of IMH on ventricular function and volumes could be demonstrated, therefore it might be considered to be a potentially important prognostic factor.

\section{Limitations}

This is a retrospective study on limited patients with acute reperfused ST-elevation myocardial infarction. A prospective study on a bigger study cohort would be desirable to confirm our results and even more important to confirm the prognostic significance of IMH in this group of patients.

As a result of time constraints in this study, like in others [16], we used only one single slice $\mathrm{T}_{2}{ }^{*}$ mapping sequence in the most representative slice in the middle of the myocardial oedema. An additional retrospective analysis of our data revealed that that was always in agreement with the centre of the LGE area. More slices could not be acquired and therefore possible haemorrhage in other areas might be missed. Therefore, it can be considered that the frequency of IMH is probably even higher than described in the present study. Further studies should therefore use a whole heart $\mathrm{T}_{2}{ }^{*}$ mapping approach. We also could not compare the total size of IMH to the size of HIC or MVO because of the one single slice $\mathrm{T}_{2}{ }^{*}$ mapping.

The period of time after infarction at which CMR was performed could also have been an important influencing factor for the IMH detection rate, because of the different degradation stages of haemoglobin, which have an effect on the signal intensity $[17,48,49]$. In this study the CMR analysis was performed within 8 days after infarction (mean 2.8 days). It is known that the oxyhaemoglobin of fresh bleeding does not have any paramagnetic effect and therefore 
can not be detected by $\mathrm{T}_{2}{ }^{*}$-weighted MRI. As a result of oxidative denaturation, deoxyhaemoglobin with its detectable paramagnetic effects occurs usually after $12-72 \mathrm{~h}$, which is known from cerebral MRI studies [48]. Therefore, it can be hypothesised that in these patients additional haemorrhage may have been detected if MR imaging had been performed later. In addition to that, Kali et al. described the good commitment of $\mathrm{T}_{2}{ }^{*}$-weighted CMR for the assessment of changes in iron deposition in postinfarcted myocardium [33, 34]. The paramagnetic effects of iron are still visible on $\mathrm{T}_{2}{ }^{*}-$ weighted images after months.

\section{Conclusions}

IMH is a frequent finding in reperfused STEMI associated with reduced ventricular function and myocardial damage, which can be assessed by CMR. Our data indicates - in concordance with other recently published data [33-36] - that $\mathrm{T}_{2}{ }^{*}$ mapping seems to be more suitable than $\mathrm{T}_{2}$-weighted images alone for the detection of IMH in reperfused acute myocardial infarction. Despite the fact that it is rather closely correlated with a HIC in $\mathrm{T}_{2}$-weighted images and MVO in LGE images, it can also occur alone according to our results.

In a larger trial with additional follow-up examinations and especially the use of a full left ventricular coverage of $\mathrm{T}_{2}{ }^{*}$ mapping, it has to be proven if this is really a separate phenomenon to MVO with a clinical and prognostic impact or just another possibility to detect MVO with a higher sensitivity as compared to $\mathrm{T}_{2}$-weighted STIR and LGE sequences. However, this may allow for a better risk stratification in patients after acute reperfused myocardial infarction.

\begin{abstract}
Acknowledgements The scientific guarantor of this publication is Prof. Dr. Matthias Gutberlet. The authors of this manuscript declare no relationships with any companies whose products or services may be related to the subject matter of the article. The authors state that this work has not received any funding. Dr. Martin Mende kindly provided statistical advice for this manuscript. Institutional review board approval was obtained. Written informed consent was obtained from all subjects (patients) in this study. Some study subjects or cohorts have been previously reported [25]. Methodology: retrospective, observational, performed at one institution.
\end{abstract}

Open Access This article is distributed under the terms of the Creative Commons Attribution Noncommercial License which permits any noncommercial use, distribution, and reproduction in any medium, provided the original author(s) and the source are credited.

\section{References}

1. Jaffe R, Charron T, Puley G, Dick A, Strauss BH (2008) Microvascular obstruction and the no-reflow phenomenon after percutaneous coronary intervention. Circulation 117:3152-3156
2. Higginson LA, White F, Heggtveit HA, Sanders TM, Bloor CM, Covell JW (1982) Determinants of myocardial hemorrhage after coronary reperfusion in the anesthetized dog. Circulation 65:6269

3. Beek AM, Nijveldt R, van Rossum AC (2010) Intramyocardial hemorrhage and microvascular obstruction after primary percutaneous coronary intervention. Int J Cardiovasc Imaging 26:49-55

4. Bekkers SC, Yazdani SK, Virmani R, Waltenberger J (2010) Microvascular obstruction: underlying pathophysiology and clinical diagnosis. J Am Coll Cardiol 55:1649-1660

5. Eitel I, Kubusch K, Strohm O, Desch S, Mikami Y, de Waha S, Gutberlet M, Schuler G, Friedrich MG, Thiele H (2011) Prognostic value and determinants of a hypointense infarct core in T2-weighted cardiac magnetic resonance in acute reperfused ST-elevationmyocardial infarction. Circ Cardiovasc Imaging 4:354-362

6. Fishbein MC, Y-Rit J, Lando U, Kanmatsuse K, Mercier JC, Ganz W (1980) The relationship of vascular injury and myocardial hemorrhage to necrosis after reperfusion. Circulation 62:1274-1279

7. Ochiai K, Shimada T, Murakami Y, Ishibashi Y, Sano K, Kitamura J, Inoue S, Murakami R, Kawamitsu H, Sugimura K (1999) Hemorrhagic myocardial infarction after coronary reperfusion detected in vivo by magnetic resonance imaging in humans: prevalence and clinical implications. J Cardiovasc Mag Reson 1:247-256

8. Basso C, Corbetti F, Silva C, Abudureheman A, Lacognata C, Cacciavillani L, Tarantini G, Marra MP, Ramondo A, Thiene G, Iliceto S (2007) Morphologic validation of reperfused hemorrhagic myocardial infarction by cardiovascular magnetic resonance. Am J Cardiol 100:1322-1327

9. Van den Bos EJ, Baks T, Moelker AD, Kerver W, van Geuns RJ, van der Giessen WJ, Duncker DJ, Wielopolski PA (2006) Magnetic resonance imaging of haemorrhage within reperfused myocardial infarcts: possible interference with iron oxide-labelled cell tracking? Eur Heart J 27:1620-1626

10. Ghugre NR, Ramanan V, Pop M, Yang Y, Barry J, Qiang B, Connelly KA, Dick AJ, Wright GA (2011) Quantitative tracking of edema, hemorrhage, and microvascular obstruction in subacute myocardial infarction in a porcine model by MRI. Magn Reson Med 66:1129-1141

11. Kumar A, Green JD, Sykes JM, Ephrat P, Carson JJ, Mitchell AJ, Wisenberg G, Friedrich MG (2011) Detection and quantification of myocardial reperfusion hemorrhage using $\mathrm{T} 2{ }^{*}$-weighted CMR. JACC Cardiovasc Imaging 4:1274-1283

12. Yellon DM, Hausenloy DJ (2007) Myocardial reperfusion injury. N Engl J Med 357:1121-1135

13. Dirksen MT, Laarman GJ, Simoons ML, Duncker DJ (2007) Reperfusion injury in humans: a review of clinical trials on reperfusion injury inhibitory strategies. Cardiovasc Res 74:343-355

14. Asanuma T, Tanabe K, Ochiai K, Yoshitomi H, Nakamura K, Murakami Y, Sano K, Shimada T, Murakami R, Morioka S, Beppu S (1997) Relationship between progressive microvascular damage and intramyocardial hemorrhage in patients with reperfused anterior myocardial infarction: myocardial contrast echocardiographic study. Circulation 96:448-453

15. Ganame J, Messalli G, Dymarkowski S, Rademakers FE, Desmet W, Van de Werf F, Bogaert J (2009) Impact of myocardial haemorrhage on left ventricular function and remodelling in patients with reperfused acute myocardial infarction. Eur Heart J 30:1440-9

16. O'Regan DP, Ahmed R, Karunanithy N, Neuwirth C, Tan Y, Durighel G, Hajnal JV, Nadra I, Corbett SJ, Cook SA (2009) Reperfusion hemorrhage following acute myocardial infarction: assessment with $\mathrm{T}^{*}$ mapping and effect on measuring the area at risk. Radiology 250:916-922

17. Bradley WG Jr (1993) MR appearance of hemorrhage in the brain. Radiology 189:15-26

18. Parizel PM, Makkat S, Van Miert E, Van Goethem JW, van den Hauwe L, De Schepper AM (2001) Intracranial hemorrhage: principles of CT and MRI interpretation. Eur Radiol 11:1770-1783 
19. Friedrich MG, Abdel-Aty H, Taylor A, Schulz-Menger J, Messroghli D, Dietz R (2008) The salvaged area at risk in reperfused acute myocardial infarction as visualized by cardiovascular magnetic resonance. J Am Coll Cardiol 51:1581-1587

20. O'Regan DP, Ahmed R, Neuwirth C, Tan Y, Durighel G, Hajnal JV, Nadra I, Corbett SJ, Cook SA (2009) Cardiac MRI of myocardial salvage at the peri-infarct border zones after primary coronary intervention. Am J Physiol Heart Circ Physiol 297: H340-346

21. Eitel I, Desch S, Fuernau G, Hildebrand L, Gutberlet M, Schuler G, Thiele H (2010) Prognostic significance and determinants of myocardial salvage assessed by cardiovascular magnetic resonance in acute reperfused myocardial infarction. J Am Coll Cardiol 55: 2470-2479

22. Cannan C, Eitel I, Hare J, Kumar A, Friedrich M (2010) Hemorrhage in the myocardium following infarction. JACC Cardiovasc Imaging 3:665-668

23. Thiele H, Wöhrle J, Neuhaus P, Brosteanu O, Sick P, Prondzinsky R, Birkemeyer R, Wiemer M, Kerber S, Schuehlen H, Kleinertz K, Axthelm C, Zimmermann R, Rittger H, Braun-Dullaeus RC, Lauer B, Burckhardt W, Ferrari M, Bergmann MW, Hambrecht R, Schuler G, Abciximab Intracoronary versus intravenously Drug Application in ST-Elevation Myocardial Infarction (AIDA STEMI) Investigators (2010) Intracoronary compared with intravenous bolus abciximab application during primary percutaneous coronary intervention: design and rationale of the Abciximab Intracoronary versus intravenously Drug Application in ST-Elevation Myocardial Infarction (AIDA STEMI) trial. Am Heart J 159:547-554

24. Thiele H, Wöhrle J, Hambrecht R, Rittger H, Birkemeyer R, Lauer B, Neuhaus P, Brosteanu O, Sick P, Wiemer M, Kerber S, Kleinertz K, Eitel I, Desch S, Schuler G (2012) Intracoronary versus intravenous bolus abciximab during primary percutaneous coronary intervention in patients with acute ST-elevation myocardial infarction: a randomised trial. Lancet 379:923-931

25. Eitel I, Wöhrle J, Suenkel H, Meissner J, Kerber S, Lauer B, Pauschinger M, Birkemeyer R, Axthelm C, Zimmermann R, Neuhaus P, Brosteanu O, de Waha S, Desch S, Gutberlet M, Schuler G, Thiele H (2013) Intracoronary compared with intravenous bolus abciximab application during primary percutaneous coronary intervention in ST-segment elevation myocardial infarction: cardiac magnetic resonance substudy of the AIDA STEMI trial. J Am Coll Cardiol 61:1447-1454

26. Chesebro JH, Knatterud G, Roberts R, Borer J, Cohen LS, Dalen J, Dodge HT, Francis CK, Hillis D, Ludbrook P (1987) Thrombolysis in myocardial infarction (TIMI) trial, phase I: a comparison between intravenous tissue plasminogen activator and intravenous streptokinase. Clinical findings through hospital discharge. Circulation 76: $142-154$

27. Grothoff M, Elpert C, Hoffmann J, Zachrau J, Lehmkuhl L, de Waha S, Desch S, Eitel I, Mende M, Thiele H, Gutberlet M (2012) Right ventricular injury in ST-elevation myocardial infarction: risk stratification by visualization of wall motion, edema, and delayedenhancement cardiac magnetic resonance. Circ Cardiovasc Imaging 5:60-68

28. Gutberlet M, Abdul-Khaliq H, Grothoff M, Schröter J, Schmitt B, Röttgen R, Lange P, Vogel M, Felix R (2003) Evaluation of left ventricular volumes in patients with congenital heart disease and abnormal left ventricular geometry. Comparison of MRI and transthoracic 3-dimensional echocardiography. RöFo 175:942-951

29. Shapiro EP, Rogers WJ, Beyar R, Soulen RL, Zerhouni EA, Lima JA, Weiss JL (1989) Determination of left ventricular mass by magnetic resonance imaging in hearts deformed by acute infarction. Circulation 79:706-711

30. Lotan CS, Bouchard A, Cranney GB, Bishop SP, Pohost GM (1992) Assessment of postreperfusion myocardial hemorrhage using proton NMR imaging at 1.5 T. Circulation 86:1018-1025
31. Lotan CS, Miller SK, Cranney GB, Pohost GM, Elgavish GA (1992) The effect of postinfarction intramyocardial hemorrhage on transverse relaxation time. Magn Reson Med 23:346-355

32. Zia MI, Ghugre NR, Connelly KA, Strauss BH, Sparkes JD, Dick AJ, Wright GA (2012) Characterizing myocardial edema and hemorrhage using quantitative $\mathrm{T} 2$ and $\mathrm{T} 2{ }^{*}$ mapping at multiple time intervals post ST-segment elevation myocardial infarction. Circ Cardiovasc Imaging 5:566-572

33. Kali A, Kumar A, Cokic I, Tang RL, Tsaftaris SA, Friedrich MG, Dharmakumar R (2013) Chronic manifestation of postreperfusion intramyocardial hemorrhage as regional iron deposition: a cardiovascular magnetic resonance study with ex vivo validation. Circ Cardiovasc Imaging 6:218-228

34. Kali A, Tang RL, Kumar A, Min JK, Dharmakumar R (2013) Detection of acute reperfusion myocardial hemorrhage with cardiac MR imaging: T2 versus T2. Radiology 269:387-395

35. Jackowski C, Christe A, Sonnenschein M, Aghayev E, Thali MJ (2006) Postmortem unenhanced magnetic resonance imaging of myocardial infarction in correlation to histological infarction age characterization. Eur Heart J 27:2459-2467

36. O'Regan DP, Ariff B, Neuwirth C, Tan Y, Durighel G, Cook SA (2010) Assessment of severe reperfusion injury with T2* cardiac MRI in patients with acute myocardial infarction. Heart 96: $1885-1891$

37. Gutberlet M, Fröhlich M, Mehl S, Amthauer H, Hausmann H, Meyer R, Siniawski H, Ruf J, Plotkin M, Denecke T, Schnackenburg B, Hetzer R, Felix R (2005) Myocardial viability assessment in patients with highly impaired left ventricular function: comparison of delayed enhancement, dobutamine stress MRI, end-diastolic wall thickness, and TI201-SPECT with functional recovery after revascularization. Eur Radiol 15:872-880

38. Husser O, Monmeneu JV, Sanchis J, Nunez J, Lopez-Lereu MP, Bonanad C, Chaustre F, Gomez C, Bosch MJ, Hinarejos R, Chorro FJ, Riegger GA, Llacer A, Bodi V (2012) Cardiovascular magnetic resonance-derived intramyocardial hemorrhage after STEMI: Influence on long-term prognosis, adverse left ventricular remodeling and relationship with microvascular obstruction. Int J Cardiol. doi:10. 1016/j.ijcard.2012.05.055

39. Ahmed N, Carrick D, Layland J, Oldroyd KG, Berry C (2012) The role of cardiac magnetic resonance imaging (MRI) in acute myocardial infarction (AMI). Heart Lung Circ 22:243-255

40. Pedersen SF, Thrysøe SA, Robich MP, Paaske WP, Ringgaard S, Bøtker HE, Hansen ES, Kim WY (2012) Assessment of intramyocardial hemorrhage by T1-weighted cardiovascular magnetic resonance in reperfused acute myocardial infarction. J Cardiovasc Magn Reson 14:59-67

41. Bekkers SC, Smulders MW, Passos VL, Leiner T, Waltenberger J, Gorgels AP, Schalla S (2010) Clinical implications of microvascular obstruction and intramyocardial haemorrhage in acute myocardial infarction using cardiovascular magnetic resonance imaging. Eur Radiol 20:2572-2578

42. Wiesmann M, Mayer TE, Yousry I, Hamann GF, Bruckmann H (2001) Detection of hyperacute parenchymal hemorrhage of the brain using echo-planar T2*-weighted and diffusion-weighted MRI. Eur Radiol 11:849-853

43. Linfante I, Llinas RH, Caplan LR, Warach S (1999) MRI features of intracerebral hemorrhage within 2 hours from symptom onset. Stroke 30:2263-2267

44. Robbers LF, Eerenberg ES, Teunissen PF, Jansen MF, Hollander MR, Horrevoets AJ, Knaapen P, Nijveldt R, Heymans MW, Levi MM, van Rossum AC, Niessen HW, Marcu CB, Beek AM, van Royen N (2013) Magnetic resonance imaging-defined areas of microvascular obstruction after acute myocardial infarction represent microvascular destruction and haemorrhage. Eur Heart J 34:2346-2353

45. Amabile N, Jacquier A, Shuhab A, Gaudart J, Bartoli JM, Paganelli F, Moulin G (2012) Incidence, predictors, and prognostic value of 
intramyocardial hemorrhage lesions in ST elevation myocardial infarction. Catheter Cardiovasc Interv 79:1101-1108

46. Chen ZM, Pan HC, Chen YP et al (2005) Early intravenous then oral metoprolol in 45,852 patients with acute myocardial infarction: randomised placebo-controlled trial. Lancet 366:1622-1632

47. Antman EM, Hand M, Armstrong PW et al (2008) 2007 focused update of the ACC/AHA 2004 guidelines for the management of patients with ST-elevation myocardial infarction: a report of the
American College of Cardiology/American Heart Association Task Force on Practice Guidelines. J Am Coll Cardiol 51:210 247

48. Anzalone N, Scotti R, Riva R (2004) Neuroradiologic differential diagnosis of cerebral intraparenchymal hemorrhage. Neurol Sci. doi: 10.1007/s10072-004-0205-8

49. Wu KC (2012) CMR of microvascular obstruction and hemorrhage in myocardial infarction. J Cardiovasc Magn Reson 14:68 